\title{
(2) OPEN ACCESS \\ People with amyotrophic lateral sclerosis and their caregivers: what matters most?
}

\author{
Paola Brunori (D) ,' Maria Grazia Celani, ${ }^{1}$ Angelo Alberto Bignamini, ${ }^{2}$ \\ Marzia Carlini, ${ }^{1}$ Rossella Papetti, ${ }^{1}$ Maria Vittoria Ercolani, ${ }^{1}$ \\ Luisa Baiocco, ${ }^{1}$ Gaetano Armato, ${ }^{1}$ Teresa Anna Cantisani ${ }^{1}$
}

- Additional material is published online only. To view please visit the journal online (http://dx.doi.org/10.1136/ bmjspcare-2020-002741)

${ }^{1}$ Neurophysiopathology, Perugia Hospital, Perugia, Italy

${ }^{2}$ School of Specialization in Hospital Pharmacy, University of Milan, Milan, Lombardia, Italy

\section{Correspondence to} Dr Paola Brunori,

Neurophysiopathology, Azienda Ospedaliera di Perugia, Perugia 06129, Italy;

paola.brunori@ospedale. perugia.it

Received 22 October 2020 Revised 8 February 2021 Accepted 15 February 2021

\section{Check for updates}

(C) Author(s) (or their employer(s)) 2021. Re-use permitted under CC BY-NC. No commercial re-use. See rights and permissions. Published by BMJ

To cite: Brunori $P$, Celani MG, Bignamini AA, et al. BMJ

Supportive \& Palliative

Care Epub ahead of

print: [please include Day

Month Year]. doi:10.1136/

bmjspcare-2020-002741

\section{ABSTRACT}

Objectives The aim of this study is to collect the perspectives and values of people affected by amyotrophic lateral sclerosis (ALS) and their carers to offer clinicians, researchers and policymakers aspects which are precious in prioritising future research questions and reshaping care service organisations in a participatory approach.

Design and setting Cohort study using ALS Umbria, the electronic database in Italy.

Participants Eleven patients and 33 carers who agreed to participate in the study were divided into six focus groups by 'status' (patient or carer) and by four severity levels of 'burden of disease'.

Methods A semiquantitative analysis was undertaken. Each recorded group discussion was transcribed into text file and independently read by two psychologists and two ALS specialists to blindly identify needs, emotions and medical issues, which are the key semantic meanings expressed. Any disagreement in interpretation was resolved through consultation among authors.

Results Carers pronounced significantly more words related to patient's disease burden they cared. $40 \%$ of subjects expressed the need for 'assistance', regardless of the disease burden. 'Anger' alone represented more than 1/4 of all expressed emotions and was more common in patients than in carers (73\% vs $36 \%$, $\mathrm{p}=0.077$ ). The most frequent medical issue expressed by $1 / 3$ of participants was 'difficulty in communication'.

Conclusion This study has given voice to the expectations of those affected by the burden of ALS. 'Welfare assistance', 'anger management' and resolution of 'difficulties in communication' represent issues that need to be analysed in a common prioritised research agenda with sensible and shared outcome measures to implement patient-centred medicine.

\section{Key messages}

What was already known?

- Qualitative studies highlight healthcare needs of people with ALS.

- Research initiatives bring together different stakeholder perspectives and arenas.

What are the new findings?

- Semi-quantitative data acquired through focus-groups, showing multi-professional assistance, patient and carer's anger, difficulties in communication with health professionals, are topics to explore.

What is their significance?

- Clinical: improve patient-centred medicine.

- Research: need for shared topics in future ALS studies.

\section{INTRODUCTION}

Amyotrophic lateral sclerosis (ALS) is a fatal neurodegenerative disease characterised by progressive muscular paralysis reflecting the degeneration of motor neurons in the cerebral cortex, brainstem and spinal cord, generally rapid and leading to death in 2-4 years. ${ }^{1}$

Despite increased knowledge about the role of genetic factors at the basis of different types of ALS disease, ${ }^{2}$ the aetiology of this disease remains largely unknown. Management of affected individuals is essentially symptom based and available disease-modifying treatments have a modest effect in slowing disease progression $^{3}$ or are recommended in selected subgroups of patients at early stage. $^{4}$

Care of people with ALS is complex and requires a multidisciplinary team approach $^{5} 6$ to improve patient quality of life and survival, ${ }^{7-9}$ although from the point of view of patients and their families, 
there are still many aspects which need to be attended to. ${ }^{10}$ Progressive loss of autonomy, uncertainty about timing when invasive procedures are required and lack of prognostic predictors regarding end of life can severely impact the living conditions of patients. The physical and psychological toll for patients, carers and health professionals is significantly high. The aim of this work is to elicit the voice of patients and carers, their perspectives, ideas and values to offer clinicians, researchers and policymakers new indications and suggestions. This 'participatory approach' could bring together different stakeholder groups to identify patient-centred questions to prioritise the future research agenda and reshape care service organisations in a joint effort.

\section{MATERIALS AND METHODS Population}

We invited people with ALS and their carers attending the outpatient service of the Neurophysiopathology Department, Perugia Hospital, Italy, to participate to focus groups. Patients had a diagnosis of definite, probable and probable laboratory-supported ALS, according to revised El Escorial criteria. ${ }^{11}$ Their names were taken from the ALS Umbria electronic register, containing personal data, clinical and instrumental information and patient's degree of functional impairment, evaluated by the Revised Amyotrophic Lateral Sclerosis Functional Rating Scale (ALSFRS-R). ${ }^{12}{ }^{13}$ Carers were all the people involved in the care of these patients.

Patients and carers had to be over 18 years of age and able to give informed consent (recorded or written). Those patients affected by frontal-temporal dementia, severe speech disorders or tracheotomised were excluded.

Recruitment to the focus groups started on 5 May 2018 and ended on 5 May 2019, phone call invitations were made to 81 people from the ALS database by the two psychologists involved in the study (RP, LB), with the aim of recruiting six to eight participants in each focus group. During the phone conversation, the two interviewers established the severity of disease in order to allocate each patient and carer to a specific group. Potential participants were informed about the aim, methodology and practical aspects of the study. With regard to the most severe patients, and for those who were unable to speak, only carers were invited to participate.

\section{Methodology}

Groups were stratified by participant's status (patient or carer) and by disease burden. Burden was proportional to the impact that physical or psychological problems had on patients and carers; participants were divided into four different levels of disease severity: 'Mild Disease', patient was able to walk, speak and eat; 'Intermediate Bulbar', patient was able to walk but not speak or eat; 'Intermediate Spinal', patient was unable to walk but was able to speak and eat; 'Severe Disease', patient was bedridden, unable to speak, eat or spontaneously breathe. Our classification did not take into account the common standardised ALSFRS-R, a good and easy-to-use tool to measure patient's performance and disease progression but not to evaluate burden of disease. ${ }^{14}$

Each group discussed the same topics, answering predetermined and semistructured questions (figure 1) and each session was recorded.

The methods used for organising and conducting the focus groups, transcribing the discussion into an electronic text file and classifying expressed needs, emotions, health-related issues and medical matters can be found in a previously published research paper. ${ }^{15}$ In summary, the two psychologists guided the discussions and regulated the sessions so that all participants had the opportunity to actively contribute.

Focus group transcripts were independently read by the two psychologists, to identify the key semantic meanings expressed by the participants' perceived needs, as well as the emotions regarding the disease and its consequences. Two ALS specialists (PB, MC) also examined the word files to highlight health and medical-related matters from each discussion group, giving a medical interpretation to patient and carer expressions. After this first step, the findings were discussed to compare results and identify equivalent key themes.

\section{Data analysis}

'Concordance' software ${ }^{16}$ was used to analyse the text file transcripts, using disease burden and subject status as main classification categories. Word frequency was computed after removing the usual stop words

\section{Recall the first time you were ill.}

\section{What did you feel when you were told you had the disease?}

\section{What problems did you have to face then and now?}

\section{What do you consider the most important aspects to be improved in disease care?}

Figure 1 List of semi-structured questions used in the focus groups. 
Table 1 Burden of disease participants' status in the six focus groups

\begin{tabular}{|c|c|c|c|c|}
\hline & Mild Disease & Intermediate Spinal & Intermediate Bulbar & Severe Disease \\
\hline Number of patients in each focus group & $\begin{array}{l}\text { Focus \#1: } \\
\mathbf{8}\end{array}$ & $\begin{array}{l}\text { Focus \#3: } \\
\mathbf{3}\end{array}$ & & \\
\hline Total 11 & 8 & 3 & 0 & 0 \\
\hline Number of carer in each focus group & $\begin{array}{l}\text { Focus \#2: } \\
12\end{array}$ & $\begin{array}{l}\text { Focus \#4: } \\
\mathbf{5}\end{array}$ & $\begin{array}{l}\text { Focus \#5: } \\
4\end{array}$ & $\begin{array}{l}\text { Focus \#6: } \\
12\end{array}$ \\
\hline Total 33 & 12 & 5 & 4 & 12 \\
\hline
\end{tabular}

(articles, prepositions and so on), while the number of words calculated by each subject retained the stop words. Data were reported as items (different single words) and tokens (total words). Needs and emotions and medical issues were transformed into headwords and counted with software facilities, analysed and stratified by classifiers. The results were exported and loaded into 'R' and SPSS version 22.0 for statistical analysis.

Data were reported as mean \pm SD and/or 95\% CI for normally distributed variables, median with extremes or 95\% CI for non-normally distributed variables or proportions with $95 \% \mathrm{CI}$ as appropriate and were compared by Welch's t-test and analysis of variance (ANOVA; by bootstrapping unless otherwise specified); Mann-Whitney, Jonckheere-Terpstra and Kruskal-Wallis tests, Fisher exact test and logistic regression analysis (with bootstrapping where needed) as appropriate for nominal variables.

This study was conducted in accordance with the Strengthening the Reporting of Observational Studies in Epidemiology reporting guidelines. ${ }^{17}$

\section{RESULTS}

Of the 81 patients contacted, 11 patients accepted to participate to the study, a total of 33 carers also accepted to participate. Psychologists contacted an average of eight people to get one participant because of the difficulties in patient transfers, exclusion criteria or carer's organisational complications. They were distributed into six focus groups. Patients: five women and six men, average age: 67.4 years $(\mathrm{SD} \pm 9.9)$, all classified with 'Mild Disease' and 'Intermediate Spinal' burden.
Carers: 17 women and 16 men, average age: 47.4 years (SD \pm 15.0$)$; 19 (58\%) were sons or daughters, $12(36 \%)$ were spouses, only $2(6 \%)$ were employed carers. Nineteen caregivers represented patients with a 'Severe Disease' or 'Intermediate Bulbar Disease' burden who could not directly participate to the focus groups due to the limitations of their condition (see table 1).

We calculated the mean ALSFRS-R score and subscore for each disease burden group. In clinical practice, our personal classification of disease measures the burden for patients and carers, while the scale exclusively measures function (table 2).

\section{Propensity to express}

The number of words pronounced during focus group discussions was remarkably variable across subgroups. There was no substantial difference in words pronounced by patients in the two subgroups, probably due to their limited number. For carers, the propensity to express themselves was significantly related to the disease burden of the patients they cared for (table 3), especially in the Bulbar and Severe groups, as if they would like to offer their voice to those who no long have a voice. Bootstrapping ANOVA indicated a significant effect of disease burden on the number of words pronounced per need and per emotion expressed, that should, however, be considered a possible artefact due to the asymmetry of data distribution owing to the structurally empty cells and the small number of bulbar cases (online supplemental table S-I).

Table 2 ALSFRS-R scores stratified by disease burden

\begin{tabular}{|c|c|c|c|c|c|}
\hline \multirow[b]{2}{*}{$\begin{array}{l}\text { ALSFRS-R and } \\
\text { components }\end{array}$} & \multirow[b]{2}{*}{$\begin{array}{l}\text { ALSFRS-R } \\
\text { score }\end{array}$} & \multicolumn{4}{|c|}{ Disease burden } \\
\hline & & $\begin{array}{l}\text { Mild Disease } \\
\text { subjects }=20 \\
\text { mean } \pm \text { SD }\end{array}$ & $\begin{array}{l}\text { Intermediate Spinal } \\
\text { subjects }=8 \\
\text { mean } \pm S D\end{array}$ & $\begin{array}{l}\text { Intermediate Bulbar } \\
\text { subjects }=4 \\
\text { mean } \pm \text { SD }\end{array}$ & $\begin{array}{l}\text { Severe Disease } \\
\text { subjects }=12 \\
\text { mean } \pm \text { SD }\end{array}$ \\
\hline ALSFRS-R & $\leq 48$ & $34.1 \pm 11.8$ & $36.0 \pm 7.4$ & $20.5 \pm 4.0$ & $15.3 \pm 9.6$ \\
\hline Bulbar component & $\leq 12$ & $10.1 \pm 2.3$ & $11.0 \pm 2.4$ & $7.0 \pm 2.3$ & $3.7 \pm 4.3$ \\
\hline Motor component & $\leq 24$ & $14.2 \pm 8.1$ & $13.6 \pm 5.2$ & $5.0 \pm 4.6$ & $4.7 \pm 5.2$ \\
\hline Fine motor score & $\leq 16$ & $9.5 \pm 6.2$ & $9.5 \pm 4.3$ & $3.5 \pm 2.9$ & $3.4 \pm 4.1$ \\
\hline Gross motor score & $\leq 12$ & $7.4 \pm 3.5$ & $6.5 \pm 2.8$ & $2.0 \pm 2.3$ & $2.0 \pm 2.9$ \\
\hline Respiratory component & $\leq 12$ & $9.9 \pm 3.2$ & $11.4 \pm 1.2$ & $8.5 \pm 1.7$ & $7.0 \pm 3.0$ \\
\hline
\end{tabular}

ALSFRS-R, Revised Amyotrophic Lateral Sclerosis Functional Rating Scale. 
Table 3 Median $(95 \% \mathrm{Cl}$ ) number of words pronounced during the focus groups severity

\begin{tabular}{|c|c|c|c|c|c|c|}
\hline \multirow[b]{2}{*}{ Status } & \multirow[b]{2}{*}{$\begin{array}{l}\text { Mild } \\
\text { Disease (subjects=20) }\end{array}$} & \multicolumn{2}{|l|}{ Severity } & \multirow[b]{2}{*}{$\begin{array}{l}\text { Severe Disease } \\
\text { (subjects }=12 \text { ) }\end{array}$} & \multirow[b]{2}{*}{$\begin{array}{l}\text { Total } \\
\text { (subjects=44) }\end{array}$} & \multirow[b]{2}{*}{$P$ value } \\
\hline & & $\begin{array}{l}\text { Intermediate Spinal } \\
\text { (subjects=8) }\end{array}$ & $\begin{array}{l}\text { Intermediate Bulbar } \\
\text { (subjects=4) }\end{array}$ & & & \\
\hline $\begin{array}{l}\text { Carers } \\
(\mathrm{N}=33)\end{array}$ & $\begin{array}{l}205 \\
(138 \text { to } 375) ; \text { carers }=12\end{array}$ & $\begin{array}{l}378 \\
\text { (347 to 993); carers=5 }\end{array}$ & $\begin{array}{l}1262 \\
\text { (574 to 1493); carers }=4\end{array}$ & $\begin{array}{l}624 \\
(202 \text { to } 1575) ; \\
\text { carers }=12\end{array}$ & $\begin{array}{l}375 \\
(247 \text { to } 993) ; \\
\text { carers }=33\end{array}$ & $\begin{array}{l}0.052^{*} \\
0.015 \dagger\end{array}$ \\
\hline $\begin{array}{l}\text { Patients } \\
(\mathrm{N}=11)\end{array}$ & $\begin{array}{l}517 \\
\text { (154 to } 1178) ; \text { patients }=8\end{array}$ & $\begin{array}{l}1099 \\
\text { (82 to 1825); patients=3 }\end{array}$ & - & - & $\begin{array}{l}551 \\
\text { (154 to } 1178) ; \\
\text { patients=11 }\end{array}$ & $0.838 \ddagger$ \\
\hline Total & $\begin{array}{l}275 \\
\text { (160 to } 551)\end{array}$ & $\begin{array}{l}460 \\
\text { (316 to 1099) }\end{array}$ & - & - & & \\
\hline $\begin{array}{l}\text { P } \\
\text { (Mann-Whitney) }\end{array}$ & $0.123 \S$ & $0.456 \S$ & - & - & & \\
\hline \multicolumn{2}{|c|}{$\begin{array}{l}\text { P } \\
\text { (ANOVA by bootstrapping) }\end{array}$} & $\begin{array}{l}0.141 \text { (status); } \\
0.128 \text { (disease burden); } \\
0.890 \text { (interaction) }\end{array}$ & & & & \\
\hline
\end{tabular}

*Kruskal-Wallis test, univariate, comparing severity within status.

†Jonckheere-Terpstra test, univariate, comparing severity within status, on the assumption of ordered response.

$\ddagger$ Mann-Whitney U test, univariate, comparing severity within status.

$\S M a n n-W h i t n e y U$ test, univariate, comparing status within severity.

ANOVA, analysis of variance.

\section{Needs expressed}

Overall, 18 different needs were expressed 172 times by 35 subjects, 9 subjects failed to express any identifiable need. 'Assistance' and 'reference person' were the needs most expressed as well as the needs most often expressed by subjects. In terms of relevance for the individual, as estimated by the mean number of expressions per subject, the most relevant needs were 'belonging/normality', 'assistance' and 'scientific advancement' (table 4).

\begin{tabular}{lcl}
\hline Table 4 & Distribution of expressed needs & \\
\hline & $\begin{array}{l}\text { No of expressions } \\
\text { (\% of total } \\
\text { expressions) }\end{array}$ & $\begin{array}{l}\text { Mean no of } \\
\text { expressions per } \\
\text { subject expressing }\end{array}$ \\
Needs & $38(22.1)$ & 2.00 \\
\hline 1. Assistance & $20(11.6)$ & 1.67 \\
\hline 2. Reference person & $13(7.6)$ & 1.08 \\
3. Knowledge & $15(8.7)$ & 1.36 \\
\hline 4. Planning & $14(8.1)$ & 1.40 \\
5. Support & $12(7.0)$ & 2.00 \\
\hline 6. Scientific advancement & 1.00 \\
\hline 7. Autonomy & $6(3.5)$ & 1.80 \\
8. Clarity & $9(5.2)$ & 1.00 \\
9. Comprehension & $5(2.9)$ & 1.00 \\
\hline 10. Outpouring & $5(2.9)$ & 1.00 \\
11. Sharing & $5(2.9)$ & 1.25 \\
12. Relying & $5(2.9)$ & 1.00 \\
13. Listening & $4(2.3)$ & 2.33 \\
14. Belonging/normality & $7(4.1)$ & 1.67 \\
15. Doing & $5(2.9)$ & 1.33 \\
\hline 16. Reassurance & $4(2.3)$ & 1.00 \\
17. Control/power & $3(1.7)$ & 1.00 \\
18. Respect & $2(1.2)$ & 1.46 \\
\hline Total & 172 & \\
\hline
\end{tabular}

There were no significant differences in the frequency of expressed needs between patients and carers, except for 'knowledge', which was more frequently detected among patients ( $55 \%$ patient vs $18 \%$ carer; $\mathrm{p}=0.0451$ ); in addition, the need to have a 'reference person' was expressed more often (30\% carer vs $18 \%$ patient) and represented a greater proportion of expressions ( $15 \%$ carer vs $4 \%$ patient) among carers. The need for 'scientific advancement' was almost equally reported in both groups (12\% vs 18\%) although 'belonging' and 'reassurance' were expressed only by carers (online supplemental table S-II).

When we stratified the reported 'needs' by disease burden, there was no difference in the kinds of needs expressed by subjects with all levels of disease burden. It may be noted that Severe Disease and Intermediate Bulbar cases reiterated much more frequently the need for 'reference person' (50\% Intermediate Bulbar and 41.7\% Severe Disease vs 20\% Intermediate Spinal and $12.5 \%$ Mild Disease), while 'assistance' was an important need regardless of the disease burden (online supplemental table S-III).

\section{Emotions expressed}

Overall, 18 different emotions were expressed 249 times by 41 subjects; 3 failed to express detectable emotion. 'Anger' and 'desperation' were the emotions expressed by the greatest proportion of subjects and represented the largest proportion of expressed emotions. Anger alone represented more than onefourth of all expressed emotions (27.3\%), followed by desperation and sadness. Anger was also the most relevant emotion to the individual, having been expressed 3.40 times per subject on average, followed by disorientation and desperation (table 5). 


\begin{tabular}{|c|c|c|}
\hline Emotion & $\begin{array}{l}\text { No of expressions } \\
\text { (\% of total } \\
\text { expressions) }\end{array}$ & $\begin{array}{l}\text { Mean no of } \\
\text { expressions per } \\
\text { subject expressing }\end{array}$ \\
\hline 1. Desperation & $36(14.5)$ & 1.71 \\
\hline 2. Anger & $68(27.3)$ & 3.40 \\
\hline 3. Sadness & $30(12.0)$ & 1.67 \\
\hline 4. Fear & $20(8.0)$ & 1.18 \\
\hline 5. Disorientation & $19(7.6)$ & 1.73 \\
\hline 6. Anxiety/apprehension & $11(4.4)$ & 1.22 \\
\hline 7. Resignation & $10(4.0)$ & 1.11 \\
\hline 8. Frustration & $7(2.8)$ & 1.17 \\
\hline 9. Hope & $8(3.2)$ & 1.60 \\
\hline 10. Sarcasm & $8(3.2)$ & 1.60 \\
\hline 11. Gratitude & $6(2.4)$ & 1.20 \\
\hline 12. Rejection & $5(2.0)$ & 1.00 \\
\hline 13. Acceptance & $5(2.0)$ & 1.25 \\
\hline 14. Disappointment & $5(2.0)$ & 1.25 \\
\hline 15. Exasperation & $5(2.0)$ & 1.25 \\
\hline 16. Renunciation & $3(1.2)$ & 1.00 \\
\hline 17. Surprise & $2(0.8)$ & 2.00 \\
\hline 18. Pride & $1(0.4)$ & 1.00 \\
\hline Total & 249 & 1.68 \\
\hline
\end{tabular}

'Sarcasm' was much more frequently expressed by patients $(36.4 \%)$ than carers $(3.0 \%) \quad(p=0.0105)$; 'anger' was expressed twice as often among patients as carers $(73 \%$ vs $36 \%, p=0.0777)$, this is only marginally significant possibly due to the low number of included patients. Equally, 'renunciation' was expressed more often by patients $(18 \%)$ than carers $(3 \% ;),(p=0.1495)$ (online supplemental table S-IV).

When we stratified the reported emotion by disease burden, 'sadness' (Mild Disease 60\%, Intermediate Spinal 0\%, Intermediate Bulbar 0\%, Severe Disease 50\%; $\mathrm{p}=0.0084$ ), 'acceptance' (Mild Disease 10\%, Intermediate Spinal 0\%, Intermediate Bulbar 50\%, Severe Disease 0\%, $\mathrm{p}=0.0176$ ) and 'desperation' (Mild Disease 45\%, Intermediate Spinal 37.5\%, Intermediate Bulbar 0\%, Severe Disease 75\%, p=0.0544) differed significantly, or were borderline, in their frequency. This observation, however, should be carefully considered, because of the imbalance in the number of cases in different burden categories (online supplemental table S-V).

The logistic regression analysis showed that only anger was significantly associated to the status and disease burden. Patients were 38.8 times more likely than carers to express anger (95\% CI 3.1 to 484.5 , $\mathrm{p}=0.004)$, and carers of patients with severe disease were 10.4 times more likely to express anger than subjects with, or caring for patients with mild disease (95\% CI 1.5 to $71.5, \mathrm{p}=0.024)$.

\section{Health-related issues and medical matters}

Overall, giving a medical interpretation to patient and carer expressions, 17 expressions were captured by

\begin{tabular}{|c|c|c|}
\hline Medical requirements & $\begin{array}{l}\text { No of expressions } \\
\text { (\% of total } \\
\text { expressions) }\end{array}$ & $\begin{array}{l}\text { Mean no of } \\
\text { expressions per } \\
\text { subject expressing }\end{array}$ \\
\hline 1. Difficult communication & $20(15.2)$ & 1.33 \\
\hline 2. Welfare assistance & $15(11.4)$ & 1.36 \\
\hline 3. Psychological support & $18(13.6)$ & 1.80 \\
\hline 4. New drug research & $12(9.1)$ & 1.50 \\
\hline 5. Architectural barriers & $7(5.3)$ & 1.17 \\
\hline 6. Rehabilitation & $9(6.8)$ & 1.80 \\
\hline 7. PEG aids & $6(4.5)$ & 1.20 \\
\hline 8. Dedicated home staff & $5(3.8)$ & 1.00 \\
\hline 9. Correct information & $7(5.3)$ & 1.75 \\
\hline 10. Reference person & $6(4.5)$ & 1.50 \\
\hline 11. Tracheal aids & $6(4.5)$ & 1.50 \\
\hline 12. Territorial services & $7(5.3)$ & 2.33 \\
\hline 13. Care integration & $5(3.8)$ & 1.67 \\
\hline 14. Psychological problems & $5(3.8)$ & 1.67 \\
\hline $\begin{array}{l}\text { 15. Dedicated hospital } \\
\text { staff }\end{array}$ & $2(1.5)$ & 1.00 \\
\hline 16. Autonomy & $1(0.8)$ & 1.00 \\
\hline 17. Euthanasia & $1(0.8)$ & 1.00 \\
\hline Total & 132 & 1.47 \\
\hline
\end{tabular}

PEG, percutaneous endoscopic gastrostomy.

the two neurologists. These were expressed 132 times by 36 subjects; 8 did not have identifiable expressions in the text files. The most frequently reported issues were 'difficult communication', 'welfare assistance' and 'psychological support'. The most relevant to the individual, as estimated by the mean number of expressions per subject, were 'territorial services', 'psychological support' and 'rehabilitation' (table 6).

The relevance of medical issues for subjects showed important differences by status: 'psychological support' was expressed three times more by carers than by patients ( $27 \%$ vs $9 \%$ ), accounting for $18 \%$ of all expressions among carers (only 3\% among patients), while 'rehabilitation' was expressed by $36 \%$ of patients and $3 \%$ of carers $(p=0.0105)$ (online supplemental table S-VI). The frequency of subjects requiring 'integrated care' $(p=0.0031)$, 'percutaneous endoscopic gastrostomy aids' $(p=0.0315)$ and 'territorial services' $(p=0.0353)$ differed significantly depending on disease burden, expressed only or mostly by carers of bulbar and severe patients (online supplemental table S-VII). Requirement of 'functional territorial services' was confirmed as specific for carers of severe patients, considering the relative frequency of expression (14\% of all expressions from carers of severe subjects) and repetition by subjects (2.33 repetition; data not shown).

The logistic regression analysis of the medical issues, however, indicated that only the requirement for 'rehabilitation' was weakly associated with status $(\mathrm{p}=0.067)$. 
"Assistance" from a person with ALS

"I need qualified care, I don't need a simple employed carer who helps me, with all due respect, to pee. It's more complicated than that. I don't know if it should be the doctors staying on top of my case or me telling the doctors what needs to be done."

"Reference person" from a person with ALS

"I don't know to whom I shouldo ask certain questions, I also need to be able to contact someone by phone...I might be willing to arrange a consultation about how to manage my father better"

\begin{abstract}
"Reference person" from a carer of a person with ALS
"What can I do? Should I call Emergency Services? Or the on-call doctor? Who should I call to get help in situations like this? Who is the reference person? I don't have a reference person!".
\end{abstract}

\author{
"Anger" from a person with ALS \\ "I can't stand this situation now, because I am very lucid, I have often mistreated my sons because \\ they look at me like l've lost my marbles" \\ "Anger" from a person with ALS \\ "I would like to resist, but this is insane, I will not get any better!". \\ Desperation from a carer of a person with ALS \\ "I need suggestions on how to handle these problems, because they are really complex...it's the \\ worst feeling, I haven't been able to really help, I wasn't able to help my father, I couldn't do \\ anytning to stop this disease"
}

Figure 2 Emotions and needs expressed by patients and carers; some quotes taken from the recorded focus group files. ALS, amyotrophic lateral sclerosis.

Figure 2 presents some example quotes taken from the recorded focus group files of participants.

\section{DISCUSSION}

In order to understand how people feel, function, share and compare their different points of view, we chose, among different methods, focus group discussions. The real novelty of our study is that by using text analysis techniques, we turned qualitative data into semiquantitative data. Two professional experts independently indexed the content of focus groups, separately coded important terms, and categorised open-ended common responses, reducing the gap between what people actually said and what moderators interpreted, in order to minimise interpretative biases. Agreement between the two coders was $90 \%$, the remaining $10 \%$ disagreement was resolved by discussion within the authors' group. Giving the fact that this methodology is a reproducible tool, this study can be used in other social health contexts to understand if people have similar reactions.

We grouped the participants by their status (patient or carer) and by severity of disease related to personal and carers' burden. The aim was to understand the real differences in perspectives between patients and family members and the way these perspectives change depending on disease severity.

ALS is a fatal and progressive disease with no therapeutic cure, the voices of people who have the disease and their carers can give new understanding to a sustainable and well-run collaboration of people living with the disease, clinicians, policymakers and researchers.

Clinicians can better understand that there is a significant difference between being a patient or a carer. Patients tend to go straight to the issue using few words to express a need or a medical problem, while carers need many more words. The propensity of carers to express themselves appeared substantially related to the disease burden of the patient they care for. This could be due to their willingness to communicate with other people, health professionals included, at a time when they are alone in managing a complex disease. This is indeed a common experience for physicians managing this condition and it becomes important to recommend that they reinforce what they are already certainly doing in their clinical practice, giving special attention to patients who are silent or have difficulty in speaking and who are often overlooked due to carers' well-intentioned involvement. The most expressed 'needs' emerging from all participants were 'assistance', followed by 'reference person' and 'knowledge'. 'Assistance' refers to the option to access tailored and more dedicated health services. 'Reference person' and 'knowledge' hold different levels of importance depending on status. Patients consider 'knowledge' to be particularly important: people living with ALS wish to have the opportunity to compare their experiences with other patients, to support each other, to have a deeper understanding of the medical aspects, to control their disease and medications, and consequently, reduce fear and plan their life-sustaining treatments in advance. Carers express 
the need for a 'reference person', the more severe the disease, the greater the need is. The ideal 'reference person' should be someone able to give explanations about the disease, offering professional information and education on the various challenges of caring for ill persons to family and professional caregivers, helping to solve the myriad of problems patients have to deal with, and helping them to navigate the convoluted health system.

In the relationship between patients, carers and health providers, we all need to bear in mind that emotions play an important role; in fact, the most expressed 'emotions' were anger, desperation and disorientation. Anger is so important that in the logistic regression analysis it was the only factor associated in a significant way to status $(\mathrm{p}=0.004)$ and disease burden $(\mathrm{p}=0.024)$.

How these feelings negatively affect both the involved people's quality of life as well as the quality of clinical care is an important topic to be explored not only by clinicians.

Moreover, to verify if there is a gap between what patients say and what doctors hear, ${ }^{18}$ two ALS specialists independently noted that 'difficult communication', 'welfare assistance' and 'psychological support' were the most relevant issues discussed, this last was especially crucial for carers.

The fact that the two ALS specialists independently interpreted similar issues that were highlighted by the two psychologists regarding the text files from the focus groups of patients and carers allow us to speculate that specific training in psychological matters can enhance the sensibilities of health professionals to bridge this gap in understanding the different points of view.

Policymakers need to understand that care must be tailored to the continually changing needs of people living with ALS, characterised by the complex and diverse disabilities that deteriorate over time, until the need for end-of-life support. We have also listened to the voices of carers, it can be physically and emotionally demanding for family members to care for a person with ALS, making it necessary to help improve their lives too, as highlighted by recent UK guidelines. ${ }^{19}$

Building health pathways to coordinate multidisciplinary interventions, to integrate care processes and to enhance the quality of care based on evidence is the expectation that comes out of these discussions as already highlighted in 2009 in a Cochrane systematic review, ${ }^{6}$ integrated in a more recent review ${ }^{20}$ and confirmed in the recently published strategy for chronic degenerative disease. ${ }^{21}$

From the researcher's point of view, there are different aspects to consider: until now, based on our search of the literature, no studies have been performed to compare different psychological approaches and techniques, nor has the efficacy and effectiveness of their interventions been evaluated. In particular, the development of further specific psychological interventions, or a selected research area about existing psychological treatments applied to people with ALS, would be important to improve the impact of the disease for patients and caregivers. ${ }^{22}$

Another potential research topic highlighted by our study is the difficulty to fully capture the complexity of the disease with the ALSFRS-R. While this scale is useful in measuring the functional decline of people with ALS, it does not offer the same advantages in the later stages of the disease. ${ }^{23}$ It also fails to represent cognitive aspects and psychological problems, such as differences in personality traits that can influence the burden of disease. One patient included in this study had a low score (19/48) and was placed in the Mild Disease group due to a very positive attitude, while another had an intermediate score $(25 / 48)$ and was included in the Severe Disease group because of complete physical immobility due to a reactive serious depression.

Nevertheless, this disability scale represents the measure used to evaluate primary outcomes in the majority of ALS trials. Traditional outcome measures, survival and measures of function do not reflect patient-centred care, as revealed by our focus group discussions.

From these explored preferences and concerns raised by focus group discussions, it is mandatory to build partnerships between patients, carers, experienced clinicians, scientists and policymakers with the aim of developing an agreed on core outcome set for effective trials in ALS, an example is the 'Comet Initiative' in other diseases. ${ }^{24}$

Moreover, further research is required to find best practices for appropriate health services for people with ALS, even using study designs represented by observational studies and prognostic models to assess new paradigms of care in 'real-life' settings.

\section{CONCLUSION}

This is one of the few studies that analyses the precious information gathered directly from the people who carry the burden of this disease. This study was carried out among a population attending the 'ALS Regional Centre' in Umbria. Therefore, it may reflect the cultural and social aspects of this geographical area, along with the characteristics of the local healthcare system and environment.

The major limitations of this study are the small sample size, a well-known recurrent limit of rare diseases, and the fact that participation to the focus groups was fully voluntary. Participating subjects were a very small population of those contacted (1:8). Taking into account that participation required time and effort, it is likely that the participants were those most motivated, consequently, these results might not be extendable to the overall population. 
This focus group analysis could be considered an example of a health research priority setting exercise, where two groups of stakeholders (people with ALS and their carers) identify topics that are of the greatest importance to them, such as the most effective and efficient care models, the efficacy of psychological treatments for negative emotions and possible communication strategies. Together with the perspectives and experiences of other stakeholders, including the funding devolved to the local health system for chronic diseases, it might be clear which uncertainties are most worth trying to resolve through research in ALS. ${ }^{25-27}$

The analysis was carried out using a semiquantitative method to guarantee that the expressions used could not be misunderstood. This perspective offers the possibility of bridging the gap that exists between people who make the agenda regarding future research, and what patients and families wish to explore, helping researchers, clinicians and decisionmakers within the health systems to move towards tailored outcome measures and truly efficacious patient-centred medicine. ${ }^{28}$

Acknowledgements The authors wish to thank Kathryn Mahan, Health Department-Region of Umbria and Coordinator of the Cochrane Neurological Sciences Field for the work in revising the manuscript and verifying the text in English. The Neurophysiopathology Department of the Perugia Hospital has accepted a charity donation from a patient who participated to the focus group discussions, who expressed the desire to contribute to making this research available to everyone.

Contributors $\mathrm{PB}, \mathrm{MGC}, \mathrm{TAC}$ and $\mathrm{AB}$ were involved in all stages of the research and preparation of the manuscript for submission and consideration for publication. MC, RP, LB, MVE and GA organised focus groups, analysed text files, managed patients and carers, and revised the manuscript.

Funding The authors have not declared a specific grant for this research from any funding agency in the public, commercial or not-for-profit sectors.

Competing interests None declared.

Patient consent for publication Not required.

Ethics approval This study was approved by the CEAS Umbria Ethics Committee.

Provenance and peer review Not commissioned; externally peer reviewed.

Data availability statement All data relevant to the study are included in the article or uploaded as supplemental information. There is no other information available in addition to all the data included in our article or to the material uploaded as supplemental information.

Open access This is an open access article distributed in accordance with the Creative Commons Attribution Non Commercial (CC BY-NC 4.0) license, which permits others to distribute, remix, adapt, build upon this work noncommercially, and license their derivative works on different terms, provided the original work is properly cited, appropriate credit is given, any changes made indicated, and the use is noncommercial. See: http://creativecommons.org/licenses/by-nc/4. $0 /$.

\section{ORCID iD}

Paola Brunori http://orcid.org/0000-0002-5680-8848

\section{REFERENCES}

1 Chiò A, Logroscino G, Hardiman $\mathrm{O}$, et al. Prognostic factors in ALS: a critical review. Amyotroph Lateral Scler 2009;10:310-23.

2 Chia R, Chiò A, Traynor BJ. Novel genes associated with amyotrophic lateral sclerosis: diagnostic and clinical implications. Lancet Neurol 2018;17:94-102.

3 Miller RG, Mitchell JD, Moore DH, et al. Riluzole for amyotrophic lateral sclerosis (ALS)/motor neuron disease (MND). Cochrane Database Syst Rev 2012;330.

4 Writing Group, Edaravone (MCI-186) ALS 19 Study Group. Safety and efficacy of edaravone in well defined patients with amyotrophic lateral sclerosis: a randomised, double-blind, placebo-controlled trial. Lancet Neurol 2017;16:505-12.

5 Miller RG, Jackson CE, Kasarskis EJ, et al. Practice parameter update: the care of the patient with amyotrophic lateral sclerosis: multidisciplinary care, symptom management, and cognitive/behavioral impairment (an evidence-based review): report of the Quality Standards Subcommittee of the American Academy of Neurology. Neurology 2009;73:1227-33.

$6 \mathrm{Ng} \mathrm{L}$, Khan F, Cochrane Neuromuscular Group. Multidisciplinary care for adults with amyotrophic lateral sclerosis or motor neuron disease. Cochrane Database Syst Rev 2009;13:CD007425.

7 Traynor BJ, Alexander M, Corr B, et al. Effect of a multidisciplinary amyotrophic lateral sclerosis (ALS) clinic on ALS survival: a population based study, 1996-2000. J Neurol Neurosurg Psychiatry 2003;74:1258-61.

8 Chiò A, Bottacchi E, Buffa C, et al. Positive effects of tertiary centres for amyotrophic lateral sclerosis on outcome and use of hospital facilities. J Neurol Neurosurg Psychiatry 2006;77:948-50.

9 Rooney J, Byrne S, Heverin M, et al. A multidisciplinary clinic approach improves survival in ALS: a comparative study of ALS in Ireland and Northern Ireland. J Neurol Neurosurg Psychiatry 2015;86:496-501.

10 Ang K, Umapathi T, Tong J, et al. Healthcare needs of patients with amyotrophic lateral sclerosis (ALS) in Singapore: a patient-centred qualitative study from multiple perspectives. $J$ Palliat Care 2015;31:150-7.

11 Brooks BR, Miller RG, Swash M, et al. El Escorial revisited: revised criteria for the diagnosis of amyotrophic lateral sclerosis. Amyotroph Lateral Scler Other Motor Neuron Disord 2000;1:293-9.

12 Cedarbaum JM, Stambler N. Performance of the amyotrophic lateral sclerosis functional rating scale (ALSFRS) in multicenter clinical trials. J Neurol Sci 1997;152 Suppl 1:s1-9.

13 Cedarbaum JM, Stambler N, Malta E, et al. The ALSFRS-R: a revised ALS functional rating scale that incorporates assessments of respiratory function. BDNF ALS Study Group (phase III). J Neurol Sci 1999;169:13-21.

14 Roche JC, Rojas-Garcia R, Scott KM, et al. A proposed staging system for amyotrophic lateral sclerosis. Brain 2012;135:847-52.

15 Celani MG, Cantisani TA, Bignamini A, et al. Is it worth it, or possible, to measure what matters to patients with epilepsy and their caregivers? Epilepsy Behav 2018;78:273-9.

16 Concordance software. Available: http://www. concordancesoftware.co.uk/

17 von Elm E, Altman DG, Egger M, et al. The strengthening the reporting of observational studies in epidemiology (STROBE) statement: guidelines for reporting observational studies. Lancet 2007;370:1453-7.

18 Ofri D. What patients say, what doctors hear. Boston, Massachusetts: Beacon Press, 2017.

19 NICE guideline [NG150] Supporting adult carers, 2020. Available: https://www.nice.org.uk/guidance/ng150 
20 Hogden A, Foley G, Henderson RD, et al. Amyotrophic lateral sclerosis: improving care with a multidisciplinary approach. $J$ Multidiscip Healthc 2017;10:205-15.

21 Bloem BR, Henderson EJ, Dorsey ER, et al. Integrated and patient-centred management of Parkinson's disease: a network model for reshaping chronic neurological care. Lancet Neurol 2020;19:623-34.

22 Pagnini F, Simmons Z, Corbo M, et al. Amyotrophic lateral sclerosis: time for research on psychological intervention? Amyotroph Lateral Scler 2012;13:416-7.

23 Chiò A, Hammond ER, Mora G, et al. Development and evaluation of a clinical staging system for amyotrophic lateral sclerosis. J Neurol Neurosurg Psychiatry $2015 ; 86: 38-44$.

24 Comet initiative. Available: http://www.comet-initiative.org/

25 Liberati A. Need to realign patient-oriented and commercial and academic research. Lancet 2011;378:1777-8.

26 About priority setting partnerships. Available: https://www.jla. nihr.ac.uk/about-the-james-lind-alliance/about-psps.htm

27 Current Cochrane group priority setting projects. Available: http://www.community.cochrane.org/

28 Hogden A, Paynter C, Hutchinson K. How can we improve patient-centered care of motor neuron disease? Neurodegener Dis Manag 2020;10:95-101. 